\title{
Characterization of Rph24: A Gene Conferring Adult Plant Resistance to Puccinia hordei in Barley
}

\author{
Laura A. Ziems, Lee T. Hickey, Gregory J. Platz, Jerome D. Franckowiak, Peter M. Dracatos, \\ Davinder Singh, and Robert F. Park
}

First and second authors: The University of Queensland, Queensland Alliance for Agriculture and Food Innovation, St. Lucia, QLD 4072, Australia; third author: Department of Agriculture and Fisheries, Hermitage Research Facility, 604 Yangan Rd, Warwick, QLD 4370, Australia; fourth author: Department of Agronomy and Plant Genetics, University of Minnesota, St. Paul 55108; and fifth and sixth authors: The University of Sydney, Plant Breeding Institute Cobbitty, Private Bag 4011, Narellan, NSW 2167, Australia. Accepted for publication 5 February 2017.

\begin{abstract}
We identified Rph24 as a locus in barley (Hordeum vulgare L.) controlling adult plant resistance (APR) to leaf rust, caused by Puccinia hordei. The locus was previously reported as a quantitative trait locus in barley line ND24260-1 and named $q R p h N D$. We crossed ND24260-1 to the leafrust-susceptible standard Gus and determined inheritance patterns in the progeny. For the comparative marker frequency analysis (MFA), resistant and susceptible tails of the $\mathrm{F}_{2}$ were genotyped with Diversity Arrays Technology genotyping-by-sequencing (DArT-Seq) markers. The Rph24

locus was positioned at 55.5 centimorgans on chromosome $6 \mathrm{H}$ on the DArT-Seq consensus map. Evaluation of $\mathrm{F}_{2: 3}$ families confirmed that a single locus from ND24260-1 conferred partial resistance. The haploblock strongly associated with the Rph24 locus was used to estimate the allele frequency in a collection of 282 international barley cultivars. Rph24 was frequently paired with APR locus Rph20 in cultivars displaying high levels of APR to leaf rust. The markers identified in this study for Rph24 should be useful for marker-assisted selection.
\end{abstract}

The deployment of genetic resistance is the most economical, effective, and ecologically sustainable approach to control foliar cereal diseases. Barley leaf rust (BLR; caused by Puccinia hordei G. H. Otth) is arguably the most common and widely distributed disease of barley (Hordeum vulgare L.). Although total crop loss has not been solely attributed to BLR epidemics, yield reductions of up to $62 \%$ have been reported in susceptible varieties (Castro et al. 2012; Cotterill et al. 1992). Although a limited number of loci conferring resistance to $P$. hordei (reaction to $P$. hordei $[R p h]$ ) are currently utilized in breeding material (Park et al. 2015; Sandhu et al. 2014), their durability, diversity, and effectiveness need to be better understood if genetic resistance is to continue as a viable control option (Golan et al. 1978; Niks et al. 2000).

Resistance to rust diseases is divided into seedling and adult plant resistance (APR) (Parlevliet and Van Ommeren 1975). Seedling resistance is conferred commonly by a single major effect gene. It is typically expressed at all stages of plant development, often associated with an immune or hypersensitive response, and generally race specific in nature (Parlevliet and Van Ommeren 1975). APR is typically defined by susceptibility at the seedling stage and resistance at the adult plant stage. APR is often conferred by multiple minor effect genes, each with minor effects on the disease phenotype, and, therefore, is typically race nonspecific. Additionally, APR genes can be categorized as partial or "slow-rusting" resistance genes. Partial resistance genes influence disease parameters such as infection frequency, pustule size, and latent period, thus restricting but not completely excluding the pathogen (Qi et al. 1999). Rph genes conferring APR often provide inadequate levels of resistance when deployed alone; however, the additive or epistatic effects of multiple resistance genes has been known to provide stable resistance (Hickey et al. 2011; Marcel et al. 2007; Qi et al. 1999).

Corresponding author: L. A. Ziems; E-mail address: 1.ziems@uq.edu.au

(c) 2017 The American Phytopathological Society
To date, 23 loci conferring resistance to $P$. hordei have been formally identified from $H$. vulgare subsp. vulgare, $H$. vulgare subsp. spontaneum, and $H$. bulbosum. Seedling resistance genes account for 21 of these (Rph1 to Rph19, Rph21, and Rph22), leaving 2 APR genes: Rph20 and Rph23 (Hickey et al. 2011; Park 2003, 2008; Sandhu et al. 2012; Singh et al. 2015). Currently, only six seedling resistance genes (Rph7, Rph11, Rph14, Rph15, Rph18, and Rph21) and the two known APR genes (Rph20 and $R p h 23$ ) are effective in Australia (Park et al. 2015). The inheritance of APR genes is often complex due to the polygenic nature of the trait; hence, their integration into breeding programs can be challenging. Barley breeders have traditionally relied on seedling resistance genes (Johnston et al. 2013; Singh et al. 2002), which provide only a single genetic barrier and are rapidly overcome by the pathogen (Jin and Steffenson 1994; Parlevliet 2002). Johnson (1981) proposed the concept of durable resistance as resistance that stays effective for many generations or a long period of time in an environment favorable to the disease. APR is considered the most durable form of resistance, because the presence of multiple minoreffect resistance loci provides numerous genetic barriers against the pathogen. This allows low levels of infection, reducing the mutation pressure on the pathogen population (Golegaonkar et al. 2009; Park et al. 2015; Parlevliet and Van Ommeren 1975).

A recent study identified a quantitative trait locus (QTL) on chromosome $6 \mathrm{H}(q R p h N D)$ in a doubled-haploid population based on a cross between the North Dakotan breeding line 'ND24260-1' and Australian 'Flagship' (Rph20) barley (Hickey et al. 2011). The authors demonstrated that $q R p h N D$ conferred low levels of resistance but, when coupled with the known APR at the Rph20 locus, provided additive and stable resistance across environments. In this study, we further characterized the $q R p h N D$ QTL, crossing the resistant donor ND24260-1 with the universally susceptible 'Gus' to map the $q R p h N D$ resistance. We used comparative marker frequency analysis (MFA) in $\mathrm{F}_{2}$ tail populations that represented resistant and susceptible phenotypes. We confirmed the segregation pattern of this locus by observing the disease response for $\mathrm{F}_{2: 3}$ families. The haploblock of molecular markers closely associated with 
$q R p h N D$ was used to assess its distribution in international barley germplasm.

\section{MATERIALS AND METHODS}

Population development and pathogen material. The North Dakotan breeding line in which $q R p h N D$ was first reported, ND24260-1 (pedigree: ND19869-1//ND17274/ND19119) was crossed with Gus (PI 494521). Gus is an accepted BLR-susceptible standard (both at seedling and adult plant stages) lacking any known resistance genes, thus enabling analysis of the proposed APR gene in a susceptible background. $P$. hordei pathotype $5457 \mathrm{P}+$ (virulent for Rph1, Rph2, Rph3, Rph4, Rph6, Rph9, Rph10, Rph12, and Rph19) was used in all experiments because it is the most virulent pathotype currently present in Australia (Park et al. 2015).

Generation advance from crossing through to $\mathrm{F}_{3}$ seed harvest was conducted under controlled environmental conditions (CEC) at The University of Queensland (UQ), St. Lucia, Australia (Fig. 1). An $\mathrm{F}_{2}$ population $(n=246)$ was generated from four $F_{1}$ seeds derived from ND24260-1/Gus. Prior to sowing, the $F_{2}$ seed were imbibed with distilled water in Petri dishes lined with filter paper (Whatman, $90 \mathrm{~mm})$ for $24 \mathrm{~h}$ and then placed in a refrigerator $\left(4^{\circ} \mathrm{C}\right)$ for $48 \mathrm{~h}$ to promote synchronous germination. Germinated seed were transplanted (two per pot) into 140-mm pots (ANOVApot) filled with a potting media consisting of composted pine bark fines (70\%) and coco peat $(30 \%)$, with a $\mathrm{pH}$ range of 5.5 to 6.5 . Slow-release Osmocote fertilizer was applied at a rate of $2 \mathrm{~g} /$ pot. Plants were grown at a temperature regime of 20 and $15^{\circ} \mathrm{C}$ (day and night, respectively) with a 12-h diurnal photoperiod, using low-pressure sodium lamps to supplement natural light levels. Inoculation with $P$. hordei was performed preanthesis at the flag-1 leaf stage, as per Park and Karakousis (2002). Plants were assessed for reaction to BLR 11 days later using a 0 -to- 9 scale, where 0 is immune and 9 is very susceptible (McNeal et al. 1971). The scale provides a single-digit summary of the amount of disease and reaction type and provides differentiation among genotypes.

In total, $168 \mathrm{~F}_{2: 3}$ lines were grown and assessed at the adult plant stage in the 2015 BLR field nursery at the Plant Breeding Institute Cobbitty (PBIC) at the University of Sydney, Australia. Approximately 20 to 30 seeds of each line were sown in $0.7-\mathrm{m}$ rows spaced $0.3 \mathrm{~m}$ apart. Gus was used as a susceptible spreader and was sown every five plots to ensure uniform disease pressure across the experiment. Epidemics were created by inoculating the nurseries with a urediniospore-mineral oil suspension $(30 \mathrm{mg}$ of spores in 1.5 liters of Isopar L mineral oil) (Univar, Ingleburn, NSW, Australia), which was misted over spreader rows using an ultralow volume applicator (Microfit; Micron Sprayer Ltd., Bromyard, Herefordshire, UK). The $\mathrm{F}_{2: 3}$ families were also assessed for resistance to BLR, as per Park and Karakousis (2002), using the 0-to-9 scale (McNeal et al. 1971).

Parental genotypes ND24260-1 and Gus were included in the UQ CEC and the PBIC field nurseries and assessed for resistance to BLR as described by Park and Karakousis (2002), using the 0-to-9 scale (McNeal et al. 1971). Additionally, a screen at the seedling stage was performed on the parental genotypes in the CEC at PBIC. Seedlings were assessed for infection type using the 0-to-4 scale, as is standard for seedling screens, and converted to a 0-to-9 scale for comparison across experiments (Stakman et al. 1962; Ziems et al. 2014). All experiments were inoculated with $P$. hordei pathotype $5457 \mathrm{P}+$ over four replicates of each line, using the same seed source that was submitted for Diversity Arrays Technology genotypingby-sequencing (DArT-Seq) genotyping.

Genotyping. The leaf tissue from $\mathrm{F}_{2}$ plants was sampled prior to inoculation in the CEC and prepared for DNA extraction. The selected tail populations comprised plants representing extremely resistant and susceptible phenotypes. Criteria for plants to be selected in the resistant class were $\leq 4$ on flag- 1 and $\leq 5$ on flag- 2 leaves, and criteria for plants to be selected in the susceptible class were $>7$ on flag- 1 and $\geq 7$ on flag- 2 leaves, based on the 0 -to- 9 scale (McNeal et al. 1971). Plants with a disease response between 5 and 7 were not considered extreme enough to be selected for either of the phenotype classes. Each "tail" encompassed a range of responses typical of that class to ensure detection of partially dominant or minor genes, because rust response often varies considerably among $\mathrm{F}_{2}$ heterozygous individuals. Genomic DNA was extracted from young leaf tissue using the protocol recommended by Diversity Arrays Technology Pty. Ltd. (DArT; www.diversityarrays.com). The samples submitted to DArT for genotyping consisted of 46 resistant plants, 46 susceptible plants, and one sample of each parent. In total, 94 individuals were genotyped with DArT-Seq markers using the Barley GBS 1.0 platform, which returned 14,640 polymorphic in silico DArT-Seq presence or absence markers.

Comparative marker allele frequency analysis. Marker data were initially processed by DArT using a quantitative allele frequency analysis method, referred to here as comparative MFA. The frequency of the ND24260-1 (resistant) allele was compared with the frequency of the contrasting Gus (susceptible) allele in the $\mathrm{F}_{2}$ progeny, and the level of allelic discrimination between the two classes was calculated. A discriminant value reflecting the difference in allele frequency between the two classes was obtained for each marker (Wenzl et al. 2006, 2007). Typically, this method identifies genetic loci conditioning phenotypic characteristics with at least 5-centimorgan (cM) accuracy without the requirement of a linkage map, as long as at least 40 representative individuals for each phenotypic class are included (Wenzl et al. 2007). A simple $\chi^{2}$ test was performed at each marker to detect significant discrimination between the expected and observed allele frequencies. A differential threshold of $>0.1$ discriminant value and $P<0.01$ was used to consider a marker significantly associated with a trait, ensuring that there is a $1 \%$ probability of detecting an allele frequency difference by chance.

Selection of informative markers. Discovery studies that used biparental populations to investigate BLR QTL in the 6HL region of interest were collated. The parent contributing the allele for resistance or susceptibility in each population was also identified (Castro et al. 2012; González et al. 2012; Hickey et al. 2011; Qi et al. 1999). Of these, DArT-Seq data were available for 'Vada' (González et al. 2012), which is reported to carry the $q R p h N D$ resistance allele;

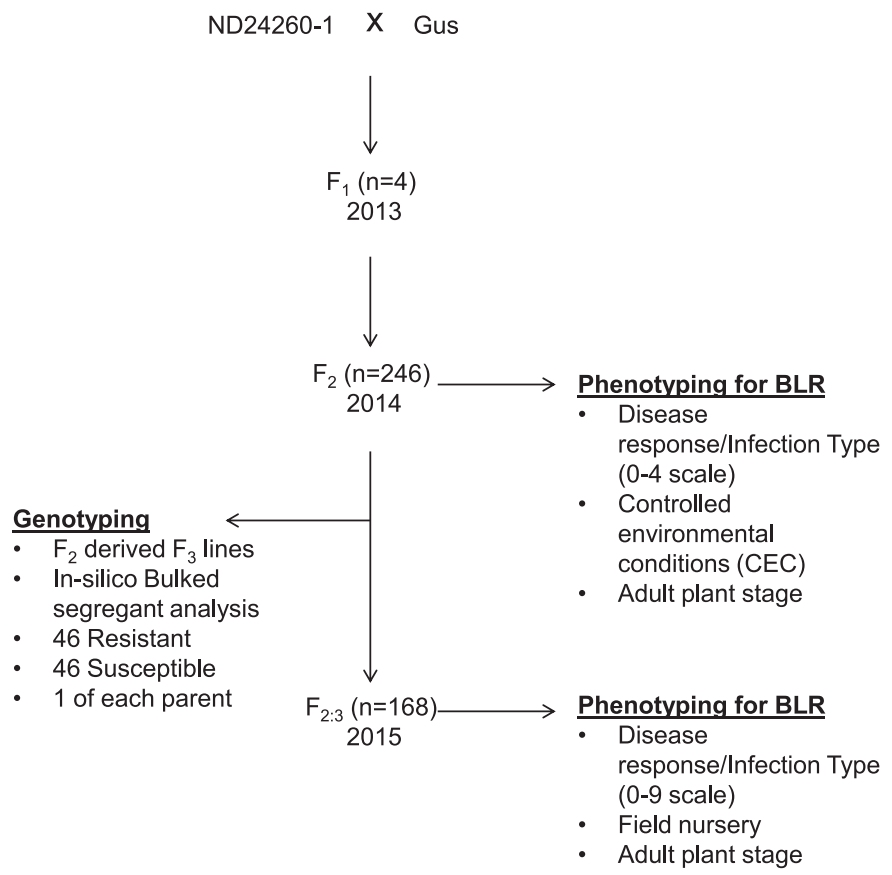

Fig. 1. Summary of population development, phenotyping, and genotyping for barley leaf rust (BLR) performed in this study. 
Flagship (Hickey et al. 2011), which was demonstrated to lack the region; and both parents 'Baronesse' ( $q$ RphND present) and 'BCD47' ( $q$ RphND absent) examined by Castro et al. (2012). The haplotype information of these parental lines was used to determine the markers that could most reliably detect the $q R p h N D$ region across diverse germplasm.

Genetic analyses. $F_{2}$ and $F_{2: 3}$ phenotypic data collected in this study were subjected to $\chi^{2}$ analyses to determine the goodness-of-fit of observed segregation within expected genetic ratios. For the $\mathrm{F}_{2}$ CEC phenotypic data, a 3:1 expected ratio was used, and, for the $\mathrm{F}_{2: 3}$ field phenotypic data, a 1:2:1 expected ratio was used. For $\chi^{2}$ analyses, all lines were placed in a response class, with ratings between 1 and 6 considered resistant and 7 to 9 considered susceptible. For the $\mathrm{F}_{2: 3}$ field generation, lines that showed a mixture of resistant and susceptible reactions from individuals within a plot were noted as segregating for disease response and a resistant and susceptible response was recorded.

Determining the frequency of $q R p h N D$ in international barley germplasm. Genotypic and phenotypic information for a collection of 282 international barley lines known to be susceptible to BLR at the seedling stage and, thus, potentially carrying sources of APR was provided by the University of Sydney (Dracatos et al. 2015). Data included 2014 PBIC field disease responses based on a coefficient of infection scale ranging from 0 to 100, and genotypes from a total of 12,241 polymorphic silico presence or absence DArT-Seq markers. Dracatos et al. (2015) determined the presence or absence of the known APR in this material using published markers for Rph20 (bPb-0837) (Hickey et al. 2011) and Rph23 (Ebmac0603) (Singh et al. 2015). Four $q R p h N D$-linked markers were selected based on haplotypes for cultivars previously reported to carry this QTL region, including Vada, Flagship, Baronesse, and BCD47. The haploblocks of these markers were used to predict presence or absence of $q R p h N D$ in the international collection. BLR response scores were available for 227 of the 282 international lines. Using these data, the mean disease response was evaluated for groups of lines that carry APR genes (Rph20, Rph23, and qRphND) alone or in combination.

QTL consensus map for leaf rust resistance on chromosome 6HL. Data on BLR resistance QTL detected in the region of interest were collated from five discovery publications (Castro et al. 2012; González et al. 2012; Hickey et al. 2011; Qi et al. 1998; Ziems et al. 2014). The integrated map published by Ziems et al. (2014) was used as a reference for QTL projection across amplified fragment length polymorphism, simple-sequence repeat, and the firstgeneration DArT markers. The centimorgan positions of individual QTL were predicted for the Bowan DArT-Seq genetic map based on bridging markers following the projection strategy detailed by Mace et al. (2009). All QTL from previous studies and the strongly associated markers with the $q R p h N D$ locus were visualized on the Bowman DArT-Seq consensus genetic map using Mapchart 2.2 (Wageningen, The Netherlands) (Voorrips 2002). Closely linked markers spanning the region were anchored onto the Morex physical map, using information provided by DArT, to determine the physical interval of the $q R p h N D$ region. Each DArT marker sequence was inputted into the integrated bioinformatics resource for crops and model plant species (Gramene; http://ensembl.gramene.org/index. html) to determine whether any of the DArT sequences were located within genes that could be candidates for disease resistance.

\section{RESULTS}

Phenotypic responses of the parental genotypes. Both parental genotypes ND24260-1 and Gus were highly susceptible at the

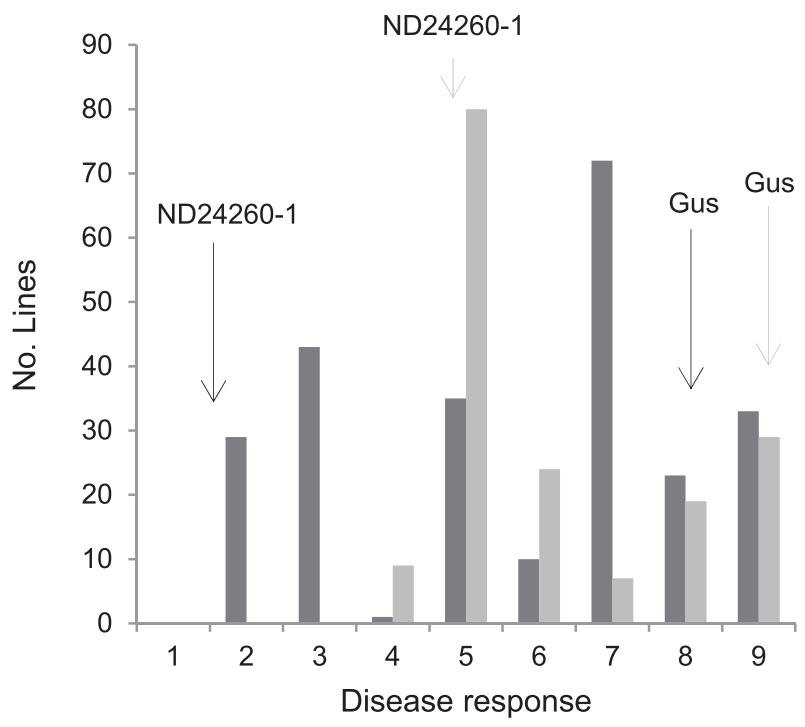

$\begin{array}{cccc} & \mathrm{n} & \mu & \sigma \\ \mathrm{F}_{2} & 246 & 5.5 & 2.5 \\ \mathrm{~F}_{2: 3} & 168 & 6.2 & 1.7\end{array}$

Fig. 2. Disease response distribution of $F_{2}$ (controlled environmental conditions at The University of Queensland) and $\mathrm{F}_{2: 3}$ (field, Plant Breeding Institute Cobbitty at the University of Sydney) progeny derived from cross ND24260-1/ Gus. Arrows indicate parental disease response in each environment.

TABLE 2. Distribution of leaf rust response and $\chi^{2}$ analysis of $F_{2}$ and $F_{3}$ progeny derived from cross ND24260-1/Gus ${ }^{\mathrm{a}}$

\begin{tabular}{lrccccc}
\hline Generation $^{\mathrm{b}}$ & Res & Seg & Sus & Genetic ratio & $\chi^{2}$ & $P$ value \\
\hline $\mathrm{F}_{2}$ & 190 & $\ldots$ & 56 & $3: 1$ & 0.66 & 0.42 \\
$\mathrm{~F}_{2: 3}$ & 46 & 84 & 38 & $1: 2: 1$ & 0.76 & 0.68 \\
\hline
\end{tabular}

${ }^{a}$ Res $=$ resistant, Seg $=$ segregating, and Sus $=$ susceptible.

${ }^{\text {b }} \mathrm{F}_{2}, \mathrm{p} 5 \%=3.84$ at $1 \mathrm{df}$, and $\mathrm{F}_{3}, \mathrm{p} 5 \%=5.99$ at $2 \mathrm{df}$.

TABLE 1. Summary of phenotypic response of parental genotypes under controlled environmental conditions (CEC) and field conditions ${ }^{\mathrm{a}}$

\begin{tabular}{|c|c|c|c|c|c|}
\hline Genotype & Seedling $(\mathrm{CEC})^{\mathrm{b}}$ & Adult $(\mathrm{CEC})^{\mathrm{c}}$ & Adult (field) ${ }^{\mathrm{b}}$ & Response $^{\mathrm{d}}$ & \\
\hline ND24260-1 & 9 & 2 & 5.25 & & \\
\hline
\end{tabular}

Gus

9

8.5

9

${ }^{a}$ Phenotype provided is the mean response of four reps assessed of each parent at each site.

b Assessment performed at Plant Breeding Institute Cobbitty, University of Sydney, Australia.

c Assessment performed at The University of Queensland, St. Lucia, Australia.

${ }^{\mathrm{d}}$ Response of representative flag-1 leaf tissue imaged in CEC at the adult plant stage. 
seedling growth stage (Table 1). Both genotypes displayed a score of 9 (McNeal et al. 1971), suggesting that they carried no effective seedling resistance genes. At the adult plant stage in the CEC, ND24260-1 showed a highly resistant response (2.0) and a moderately resistant response in the field (5.3), whereas Gus showed high levels of susceptibility in the CEC and field environments (8.5 and 9.0, respectively). Although ND24260-1 displayed a very resistant response under CEC, there were signs of sporulation on the

TABLE 3. Twenty-three markers significantly associated with $q R p h N D$ on $6 \mathrm{H}$, including Bowman genetic position, Morex physical position, discriminant value (which indicates frequency difference between classes), as well as allele present in cultivars with known resistance or susceptibility for this region

\begin{tabular}{|c|c|c|c|c|c|c|c|c|c|}
\hline \multirow[b]{2}{*}{ CloneID } & \multicolumn{2}{|c|}{ Position } & \multirow[b]{2}{*}{$\mathrm{DV}^{\mathrm{b}}$} & \multicolumn{3}{|c|}{$q R p h N D$ present } & \multicolumn{3}{|c|}{$q R p h N D$ absent } \\
\hline & Genetic $(\mathrm{cM})^{\mathrm{a}}$ & Physical (bp) & & ND24260-1 & Baronesse & Vada & Gus & Flagship & BCD47 \\
\hline $3662398^{c}$ & 45.15 & 33458920 & $0.13 * *$ & 1 & $\ldots$ & $\ldots$ & 0 & 0 & $\ldots$ \\
\hline 4790180 & 45.96 & 33458920 & $0.15 * * *$ & 1 & 0 & $\ldots$ & 0 & 0 & 0 \\
\hline 3266834 & 46.67 & 40303720 & $0.12 * *$ & 0 & 1 & $\ldots$ & 1 & 1 & 0 \\
\hline 3267276 & 46.67 & 41103520 & $0.10 * *$ & 1 & 0 & 1 & 0 & 0 & 0 \\
\hline 3271118 & 49.08 & 51143800 & $0.13 * *$ & 1 & 0 & 1 & 0 & 0 & 0 \\
\hline 3265876 & 49.52 & 66692160 & $0.12 * *$ & 0 & $\ldots$ & $\ldots$ & 1 & 1 & $\ldots$ \\
\hline $3810484^{c}$ & 49.52 & 66692160 & $0.11 * *$ & 1 & 0 & 0 & 0 & 0 & 0 \\
\hline 3272090 & 49.52 & 66692160 & $0.11 * *$ & 1 & $\ldots$ & 0 & 0 & 0 & $\ldots$ \\
\hline 3433430 & 49.65 & 70712240 & $0.11 * *$ & 0 & $\ldots$ & $\ldots$ & 1 & 1 & $\ldots$ \\
\hline 3265121 & 49.65 & 70712240 & $0.11 * *$ & 0 & $\ldots$ & 1 & 1 & 1 & $\ldots$ \\
\hline 3812668 & 50.35 & 82856800 & $0.10 * *$ & 1 & $\ldots$ & 0 & 0 & 0 & $\ldots$ \\
\hline 5239943 & 51.42 & 89226680 & $0.10 * *$ & 1 & 0 & 0 & 0 & 0 & 1 \\
\hline 3999951 & 51.42 & 89226680 & $0.10 * *$ & 0 & $\ldots$ & 1 & 1 & 1 & $\ldots$ \\
\hline 3264594 & 51.77 & 92057600 & $0.13 * *$ & 1 & 0 & 0 & 0 & 0 & 1 \\
\hline 4415543 & 51.77 & 92057600 & $0.10 * *$ & 1 & 0 & 0 & 0 & 0 & 1 \\
\hline 3263568 & 52.2 & 93003720 & $0.10 * *$ & 1 & 0 & 0 & 0 & 0 & 0 \\
\hline $3999875^{\mathrm{c}, \mathrm{d}}$ & 55.52 & 315132360 & $0.15 * *$ & 0 & 0 & 0 & 1 & 1 & 1 \\
\hline $3272559^{\mathrm{c}, \mathrm{d}}$ & 55.52 & 315132360 & $0.12 * *$ & 0 & 0 & 0 & 1 & 1 & 1 \\
\hline $3265068^{\mathrm{c}, \mathrm{d}}$ & 55.52 & 312920200 & $0.11 * *$ & 0 & $\ldots$ & 0 & 1 & 1 & $\ldots$ \\
\hline 3272212 & 56.04 & 338795280 & $0.12 * *$ & 0 & 0 & $\ldots$ & 1 & 1 & 0 \\
\hline 3270780 & 56.04 & 338795280 & $0.11 * *$ & 0 & 0 & 0 & 1 & 1 & 0 \\
\hline 3396499 & 56.04 & 338795280 & $0.11 * *$ & 1 & 1 & $\ldots$ & 0 & 0 & 1 \\
\hline $3272930^{c}$ & 56.04 & 338795280 & $0.10 * *$ & 0 & 0 & $\ldots$ & 1 & 1 & 1 \\
\hline
\end{tabular}

a Position measured in centimorgans (cM).

b Discriminant value; ** and *** indicate significant at 1 and $0.1 \%$ levels, respectively.

c Marker associated with protein coding region.

d RphqND-linked markers used for quantitative trait locus designation in international barley panel.

6H Genetic Map (cM) 6H Physical Map (Mbp)

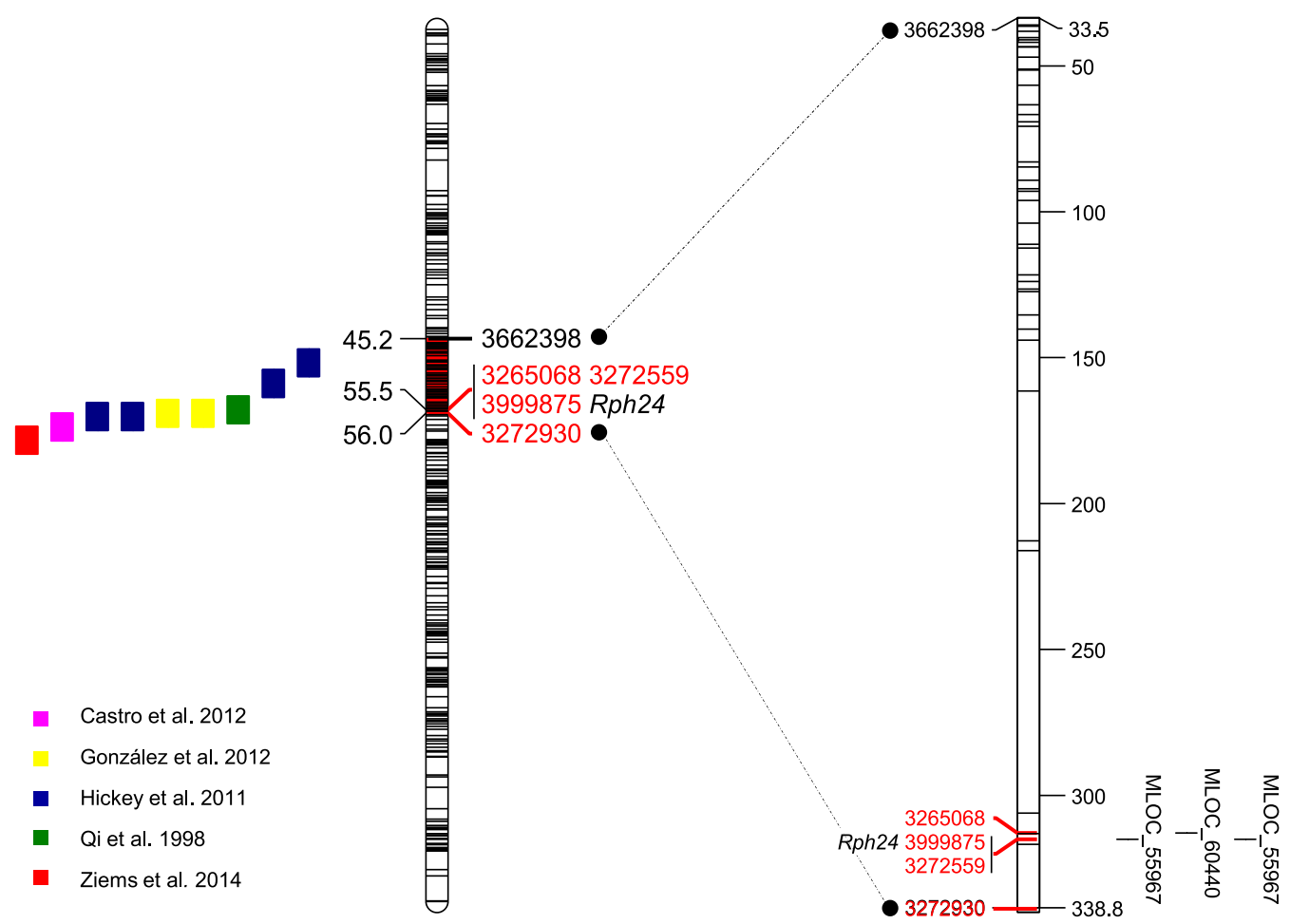

Fig. 3. Previously identified quantitative trait loci (QTL) for resistance to Puccinia hordei displayed on the Bowman chromosome $6 \mathrm{H}$ genetic map with $q R p h N D$ identified in the present study and the Morex physical map for the region of interest. Red indicates markers representing the $q R p h N D$ haplotype and black indicates flanking marker. QTL depicted on the left were collated from previous studies and confidence interval of 2 centimorgans was applied for visualization purposes. 
flag-1 and flag-2 leaves; however, pustules were sparse and restricted (Table 1).

Inheritance of resistance. Variation in levels of BLR reaction was observed throughout disease screening of the ND24260-1/Gus population (Fig. 2). In the $\mathrm{F}_{2}$ generation assessed in the CEC, a mean disease response of 5.5 with a standard deviation of 2.5 was observed. In the subsequent $\mathrm{F}_{2: 3}$ generation assessed in the field, a mean disease response of 6.2 with a standard deviation of 1.7 was observed. The segregation pattern for BLR responses was determined for the $\mathrm{F}_{2}$ plants $\left(\chi^{2} 3: 1\right.$ at $\left.1 \mathrm{df}=0.66, P=0.42\right)$ (Table 2$)$ as well as the subsequent $\mathrm{F}_{2: 3}$ families $\left(\chi^{2} 1: 2: 1\right.$ at $\left.2 \mathrm{df}=0.76, P=0.68\right)$ (Table 2), suggesting the involvement of a single locus reducing disease response.

Mapping the $R p h N D$ resistance. Comparative MFA identified 23 markers associated with resistance spanning a region of $10.9 \mathrm{cM}$ on chromosome $6 \mathrm{HL}$ of the Bowman consensus genetic map (Table 3). As expected, the allele for resistance at each marker was contributed by the donor ND24260-1. Of the nine QTL detected in the $q R p h N D$ region in previous studies (Castro et al. 2012; González et al. 2012; Hickey et al. 2011; Qi et al. 1998; Ziems et al. 2014), five colocated with the peak marker 3999875 and eight were positioned within the region of interest (i.e., 45.15 to $56.04 \mathrm{cM}$ ) (Fig. 3). This 10.9-cM interval on chromosome $6 \mathrm{HL}$ corresponded to $350.5 \mathrm{Mb}$ on the Morex physical map. Four markers $(3999875,3265068,3272559$, and 3272930) within a $0.52-\mathrm{cM}$ window were selected as the most closely linked to $q R p h N D$ (Table 3). Barley cultivars previously identified as positive for the $q R p h N D$ region carried the allele for resistance, whereas cultivars reportedly lacking the region carried the allele for susceptibility (Table 3 ).

Of the four $q R p h N D$-linked DArT-Seq markers, three were located within genes with known function. Two of the four $q R p h N D$-linked DArT (3999875 and 3272559) had the highest BLASTn similarity matches $\left(9.6 \mathrm{E}^{-31}\right)$ to the same Morex gene locus (MLOC_55967) encoding for a protein with a leucine-rich repeat and a protein kinase domain (Table 4). The third DArT-Seq marker (3265068) had the highest similarity to MLOC_60440 encoding a protein with a leucinerich repeat domain.

Frequency of APR genes in international germplasm. Of the 23 markers highly associated with $q R p h N D, 20$ were polymorphic in the international collection. In all, $24 \%$ of the accessions were positive for the four $q R p h N D$-linked markers (Table 5). Accessions that carried $q R p h N D$ markers had the following origins: Australia (16\%), Canada (20\%), China (20\%), Ethiopia (40\%), Europe (39\%), North and South America (24\%), Germany (60\%), Kenya (100\%), and Uruguay (30\%). Material originating in Algeria, Egypt, Morocco, Spain, and Sudan lacked the positive haploblock for the four $q R p h N D$-linked markers (Table 5).

Accessions positive for the Rph20-linked marker alone displayed a mean coefficient of infection (COI) of 14.5 (Table 6). When the $R p h 20$ - and the $q R p h N D$-linked markers were present in combination, the average reaction was 13.6. Notably, this gene combination was observed in $13 \%$ of the assessed material. When only the RphqND markers were present, the mean COI was 49.0. Material possessing only the Rph23-linked marker displayed a higher mean COI of 55.4. Of the international collection, $38 \%$ lacked markers for $R p h 20, R p h 23$, and $q R p h N D$ and had a mean COI of 49.1. The combination of positive markers for $R p h 20+R p h 23+q R p h N D$ occurred in only two German lines (Lenka and Line17), Rph20+ $R p h 23$ only once (Volla), and the Rph $23+q R p h N D$ combination was not observed (Fig. 4).

\section{DISCUSSION}

In this study, we characterized, mapped, and identified molecular markers closely linked with $q R p h N D$ in the region of chromosome $6 \mathrm{HL}$ where the APR locus was previously mapped (Hickey et al. 2011). Genetic analysis of the ND24260-1/Gus $F_{2: 3}$ families validated the presence of a single locus contributing resistance to $P$. hordei at the adult plant growth stage. The $q R p h N D$ locus on chromosome 6HL appears to act additively to reduce disease response when present in combination with the known APR gene $R p h 20$. To date, no previously named genes conferring APR to BLR have been located on chromosome 6HL. The seedling resistance gene Rph 11 is located on chromosome $6 \mathrm{H}$ but the distance between $R p h 11$ and $q R p h N D$ is greater than the window of linkage disequilibrium decay. Furthermore, because Rphll is a seedling resistance gene, and given the observed seedling susceptibility in both parents and

TABLE 5. Summary of international barley collection, including total accessions $(n)$ and number of lines positive for markers linked to each of the adult plant resistance (APR) genes $R p h 20, R p h 23$, and $q R p h N D$, as well as mean barley leaf rust disease response $(\mu)$ at the Plant Breeding Institute Cobbitty field site in 2014 for accessions grouped according to origin

\begin{tabular}{lrrccc}
\hline Origin & $n$ & $R p h 20$ & $R p h 23$ & $q R p h N D$ & $\begin{array}{c}\mu \text { Disease } \\
\text { response }\end{array}$ \\
\hline Algeria & 2 & 0 & 1 & 0 & $\ldots$ \\
Australia & 56 & 19 & 4 & 9 & 50.3 \\
Canada & 10 & 0 & 4 & 2 & 26.5 \\
China & 10 & 0 & 2 & 2 & 67 \\
Egypt & 15 & 0 & 4 & 0 & $\ldots$ \\
Ethiopia & 20 & 0 & 0 & 8 & $\ldots$ \\
Europe & 46 & 30 & 0 & 18 & 23.2 \\
North and & & & & & \\
$\quad$ South America & 51 & 25 & 8 & 12 & 35.2 \\
Germany & 20 & 14 & 3 & 12 & 16.1 \\
Kenya & 1 & 0 & 0 & 1 & $\ldots$ \\
Morocco & 5 & 0 & 1 & 0 & $\ldots$ \\
Spanish & 33 & 0 & 6 & 0 & 35.3 \\
Sudan & 3 & 0 & 2 & 0 & $\ldots$ \\
Uruguay & 10 & 6 & 0 & 3 & 21.7 \\
Total & 282 & 94 & 35 & 67 & $\ldots$ \\
\hline
\end{tabular}

TABLE 4. Bioinformatic analysis for Diversity Arrays Technology genotyping-by-sequencing markers within the $q R p h q N D$ region, and physical position based on Morex physical map

\begin{tabular}{|c|c|c|c|c|c|c|c|c|}
\hline CloneID & $\begin{array}{c}\text { Physical } \\
\text { position (bp) }\end{array}$ & Allele sequence & Transcript ID & E-value & UniProt & Molecular function & Biological process & Top rice hit \\
\hline 3662398 & 33458920 & $\begin{array}{c}\text { TGCAGTGACACACATATCCAATGG } \\
\text { TCAGCTTCCTTCTCAGAGCAATA } \\
\text { TCATAGCGTTTGGAGCACAATG }\end{array}$ & MLOC_6677 & $5.7 \mathrm{E}-26$ & F2CTG8 & Glutaminase activity & $\begin{array}{l}\text { Pyridoxal phosphate } \\
\text { biosynthetic process, } \\
\text { Vitamin B6 } \\
\text { biosynthetic process }\end{array}$ & $\begin{array}{l}\text { Protein pyridoxal } \\
\text { biosynthesis protein } \\
\text { PDX2, Putative, } \\
\text { Expressed }\end{array}$ \\
\hline 3810484 & 66692160 & $\begin{array}{c}\text { TGCAGTTTGCAAATGAGGAATGCA } \\
\text { TGATGAATGCGCGAGACCGAGAT } \\
\text { CGGAAGAGCGGTTCAGCAGGAA }\end{array}$ & MlLOC_5838 & $4.9 \mathrm{E}-14$ & MOXAI0 & $\begin{array}{l}\text { Calcium: proton } \\
\text { antiporter activity }\end{array}$ & $\begin{array}{l}\text { Calcium ion } \\
\text { transmembrane } \\
\text { transport }\end{array}$ & $\begin{array}{l}\text { Protein sodium/calcium } \\
\text { exchanger protein, } \\
\text { Putative, Expressed }\end{array}$ \\
\hline 3999875 & 315132360 & $\begin{array}{c}\text { TGCAGTGGAGGTCAAGCTGAGATA } \\
\text { AGGCGTGACAATGGCATATGAAA } \\
\text { CCGAAGTGTGTGGGTGTGAGAA }\end{array}$ & MLOC_55967 & $9.6 \mathrm{E}-31$ & F2DJ73 & $\begin{array}{l}\text { Protein kinase } \\
\text { activity, ATP } \\
\text { binding }\end{array}$ & Protein phosphorylation & $\begin{array}{l}\text { Protein receptor kinase, } \\
\text { putative, Expressed }\end{array}$ \\
\hline 3265068 & 312920200 & $\begin{array}{c}\text { TGCAGCTACCCGAACAACAGAATC } \\
\text { CCAGCAGGCCAGCTGAAGTAACA } \\
\text { AAATCAAAAAATTCCAAATAAA }\end{array}$ & MLOC_60440 & $9.6 \mathrm{E}-31$ & M0XIT3 & $\ldots$ & $\cdots$ & $\cdots$ \\
\hline 3272559 & 315132360 & $\begin{array}{c}\text { TGCAGCGTAGACCTTGACTCGTCA } \\
\text { AAACATGCCGCTTTTCATCTTCC } \\
\text { ACAGCCACCGCTTGCGTCGCTG }\end{array}$ & MLOC_55967 & $9.6 \mathrm{E}-31$ & F2DJ73 & $\begin{array}{l}\text { ATP binding, protein } \\
\text { kinase activity }\end{array}$ & Protein phosphorylation & $\begin{array}{c}\text { Protein receptor kinase, } \\
\text { putative, Expressed }\end{array}$ \\
\hline
\end{tabular}


the detection of resistance only at adult growth stages, it is highly unlikely that $q R p h N D$ is the same locus.

To improve the accuracy of phenotypic selections for MFA, we opted to perform screening of the $\mathrm{F}_{2}$ generation under CEC. Notably, the disease response of the ND24260-1/Gus progeny varied greatly between CEC and field screens. The enhanced resistance and greater distribution of responses observed in the CEC is most likely due to the monocyclic conditions (i.e., a single inoculation event) (Hickey et al. 2011). Additionally, partially dominant genes, especially minor genes, tend to exhibit higher rust responses in $\mathrm{F}_{2}$ heterozygotes (Golegaonkar et al. 2009; Roelfs 1988). In the field, multiple infections occur throughout the season due to exposure of the pathogen to favorable environments that promote sporulation and further infection. Multiple infection cycles create high levels of disease pressure in field screening nurseries, effectively masking minor resistance responses that act to slow down rather than inhibit infection. Phenotyping for APR at the adult stage in CEC is not common; however, when dealing with these types of resistance, it may be a useful tool, as demonstrated in this study. Although phenotyping under CEC can improve the accuracy and precision of quantifying APR, when it comes to timing of inoculation, it is important to consider when these mechanisms are "switched" on, because they are influenced by many factors such as maturity, temperature, and humidity (Hickey et al. 2011; Riaz et al. 2016; Roelfs 1988; Singh et al. 2013). Further studies could quantify the latent period conferred by $q R p h N D$, as well as evaluate any variation in levels of resistance using a range of pathotypes. Such studies could be more precisely conducted under CEC.
Based on our survey of a broader array of germplasm, when $q R p h N D$ is present alone, the gene appears to provide only a weak level of resistance and, in many cases, is almost ineffective. This could be due to genetic background effects or the presence of uncharacterized APR. Rph20, when present alone in material, showed moderate resistance with low variation across lines; however, its effect was enhanced when paired with $q R p h N D$, indicating that these BLR APR genes are potentially interactive. It appears that $q R p h N D$ and $R p h 20$ act additively in low-disease-pressure environments and interactively in high-disease-pressure environments. This is likely because partial resistance conferred by $q R p h N D$ cannot be differentiated from a susceptible genotype under high disease pressure. Similar observations have been made for genes conferring APR to rust in wheat, including the stem rust gene $S r 2$ and the leaf rust gene $L r 34$ that provided durable partial resistance for many years. However, when deployed alone, these APR genes do not provide adequate levels of resistance under high disease pressure. Furthermore, delayed expression due to environmental factors can render the plants susceptible during heavy epidemics (Ellis et al. 2014; Krattinger et al. 2013; Yildirim et al. 2012). Singh et al. (2015) and Dracatos et al. (2015) demonstrated an additive interaction between Rph20 and $R p h 23$; however, in this study, the pairing was only observed in one instance. The combination of Rph20, Rph23, and $q R p h N D$ occurred at a very low frequency; only two barley accessions from Germany (Lenka and Line 17) were positive for all three APR loci and both were highly resistant in the field over multiple seasons. However, assessment of more accessions carrying such a combination is

TABLE 6. Number of lines $(n)$ in the international barley panel positive for markers linked to adult plant resistance (APR) genes Rph20, Rph23, and $q R p h N D$, alone or in combination

\begin{tabular}{lccccccc}
\hline Lines $^{\mathrm{a}}$ & No known APR & $R p h 20$ & Rph23 & $q R p h N D$ & Rph20 + Rph23 & Rph20 +qRphND & Rph20 + Rph23 +qRphND \\
\hline$n$ & 87 & 60 & 24 & 24 & 1 & 29 & 2 \\
$\mu$ & 49.1 & 14.5 & 55.4 & 49.0 & 5 & 13.6 & 12.7 \\
$\sigma$ & 28.3 & 13.7 & 22.8 & 24.8 & $\ldots$ & 20.0 & 14.1 \\
\hline
\end{tabular}

a Mean disease response $(\mu)$ and standard deviation $(\sigma)$ are presented for each group.

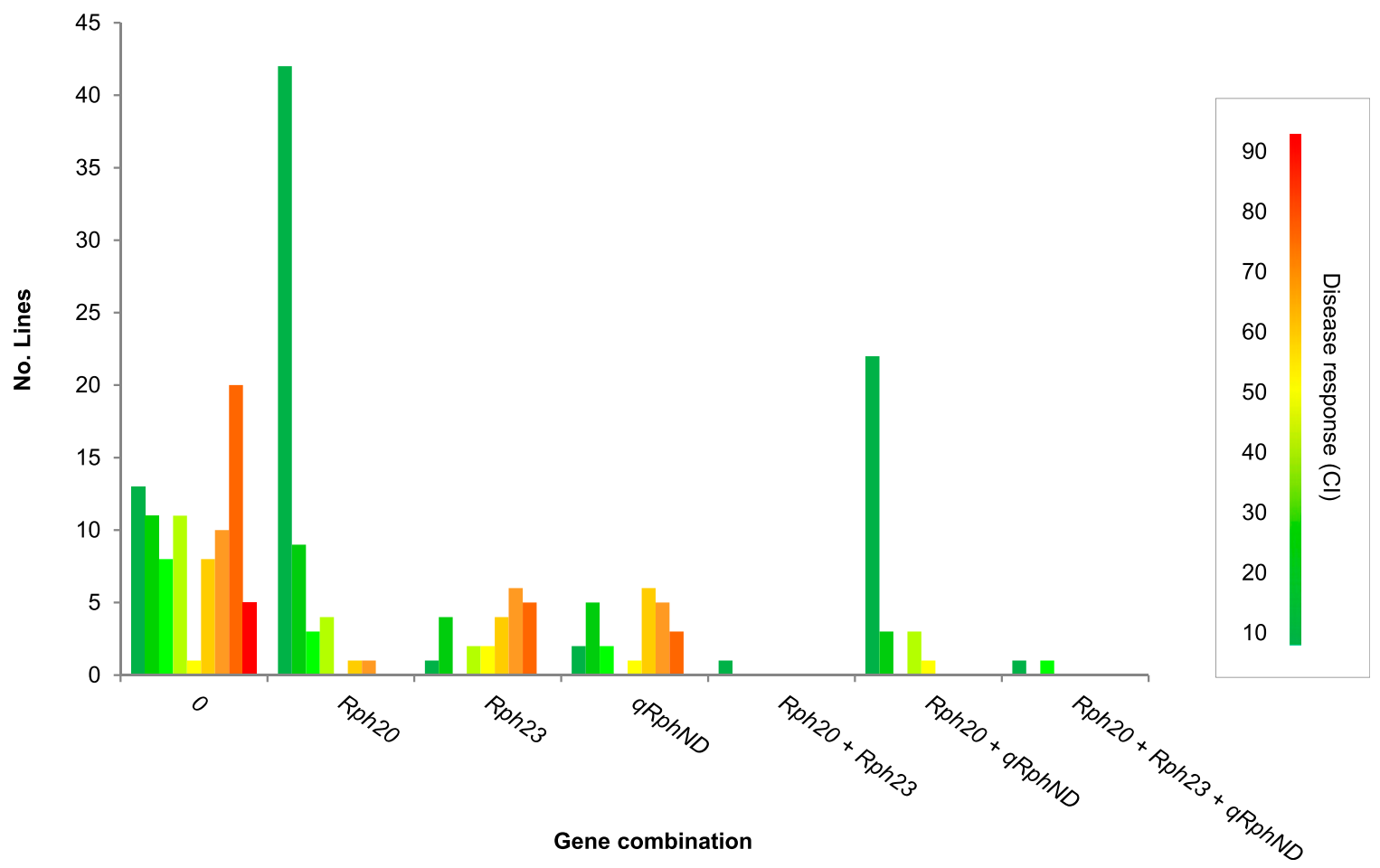

Fig. 4. Number of lines in the international barley panel positive for markers linked to adult plant resistance genes $R p h 20, R p h 23$, and $q R p h N D$, alone or in combination. Markers used to designate presence or absence of $q R p h N D$ were 3999875, 3272559, 3265068, and 3272930. Bars indicate number of lines exhibiting each disease response, reported as coefficient of infection (CI). Green represents resistance and red represents susceptibility. 
required to validate phenotype effects. Interestingly, six lines from the international collection were deemed to lack all known APR genes and displayed highly resistant reactions. The majority of these lines were of Spanish origin and one was from Germany. These lines should be further investigated to determine whether they (i) carry novel resistance loci, (ii) carry alternative alleles at known APR loci, or (iii) recombination between the linked-marker and known APR locus has occurred. The pairing of Rph2O and $q R p h N D$ was common throughout the international germplasm and provided a reduction in disease response. The high frequency of $q R p h N D$ and $R p h 20$ in this material could be attributed to the origin of the panel. For instance, production areas that have a greater prevalence of BLR such as Australia, Uruguay, and Europe showed a higher frequency of $R p h 20$ and $q R p h N D$. This is most likely due to continuous selection for resistance to BLR during cultivar development. Interestingly, both $R p h 20$ and $q R p h N D$ were segregating in all populations examined in studies that reported the $q R p h N D$ region to date (Castro et al. 2012; González et al. 2012; Hickey et al. 2011; Qi et al. 1998; Ziems et al. 2014). This likely enhanced the ability to detect the $q R p h N D$ locus.

The identification, development, and subsequent utilization of a molecular marker associated with the APR locus Rph20 (Hickey et al. 2011) and Rph23 (Singh et al. 2015) has greatly enhanced their exploitation in breeding material. Previous experience, however, suggests that deployment of single resistance factors in breeding programs is likely to place higher selection pressure on pathogen populations, leading to the breakdown of resistance. Previous studies of APR to leaf rust in wheat have demonstrated race specificity in several cases (Park and McIntosh 1994). Prior to the identification of a DNA marker closely linked with Rph20, phenotypic selection performed by breeders resulted in barley varieties carrying Rph20 in combination with other minor APR genes, as demonstrated in the international barley germplasm. The benefit in pairing APR genes is not only enhanced levels of partial resistance but also enhanced durability through additional genetic barriers. The frequency of the $R p h 20+q R p h N D$ pairing based on phenotypic selection alone highlights the value of this combination. $q R p h N D$ is a slow-rusting gene conferring partial APR. It acts to restrict but not completely avoid infection and to delay the latent period, with the result that infection is observed at the adult plant stage. The designation of $q R p h N D$ as a novel minor gene will reduce reliance upon a single resistance factor and, through pairing with $R p h 20$, it will contribute to sustainable BLR resistance.

Numerous studies have previously identified QTL for resistance to BLR in the same region of chromosome $6 \mathrm{H}$ as $q R p h N D$. In total, eight QTL from four different studies colocalized to the $q R p h N D$ genetic interval (Castro et al. 2012; González et al. 2012; Hickey et al. 2011; Qi et al. 1999), suggesting that they are likely to represent the same locus, which could be a single gene or a complex resistance gene cluster. Interestingly within the critical region (55.3 to $56.0 \mathrm{cM}$ ), three highly significant DArT-Seq markers mapped to two gene candidates with annotated protein kinase and leucinerich repeat domains. Receptor kinases that function as cell surface receptors have been previously associated with plant defense (Afzal et al. 2008; Parrott et al. 2016). Parrott et al. (2016) recently demonstrated that a protein receptor kinase underpinning the Mla locus was involved in the detection of powdery mildew (caused by Blumeria graminis f. sp. hordei) in barley. In addition, the cloned wheat APR gene Yr36 encodes a protein with kinase and a lipidbinding domain, reported to be involved in signaling ( $\mathrm{Fu}$ et al. 2009), further suggesting that such genes play a role in APR to biotrophic pathogens. However, the $q R p h N D$ region corresponded to a physical interval of $305 \mathrm{Mb}$ in the Morex genome sequence. Such a physical region contains too many possible genes to narrow down specific candidates responsible for the $q R p h N D$ resistance. Further fine mapping efforts are required to refine both the genetic and, hence, physical interval to determine the causal gene.
Based on genetic analysis, mapping, chromosomal location, and the detection of markers closely linked to $q R p h N D$, we consider it a novel and detectable locus. Therefore, $q R p h N D$ has been officially assigned the locus designation Rph24 with the resistant allele Rph24.an following consultation with Dr. Frank Ordon, Julius Kuehn Institute, Germany, in line with international protocols for disease locus designation in barley. The Rph24.an allele represents an important additional genetic resource for barley breeders as they focus more on durable BLR resistance. The fact that the Rph24.an allele is highly interactive with the Rph20.ai allele in reducing BLR severity makes it particularly useful for deployment in combination and offering prospects for durable resistance.

\section{ACKNOWLEDGMENTS}

This research was supported by the Grains Research and Development Corporation of Australia (UQ00056). We thank T. Shatte (Department of Agriculture and Fisheries) for technical assistance in the laboratory.

\section{LITERATURE CITED}

Afzal, A. J., Wood, A. J., and Lightfoot, D. A. 2008. Plant receptor-like serine threonine kinases: Roles in signaling and plant defense. Mol. Plant-Microbe Interact. 21:507-517.

Castro, A. J., Gamba, F., German, S., Gonzalez, S., Hayes, P. M., Pereyra, S., and Perez, C. 2012. Quantitative trait locus analysis of spot blotch and leaf rust resistance in the BCD47 Baronesse barley mapping population. Plant Breed. 131:258-266.

Cotterill, P. J., Rees, R. G., Platz, G. J., and Dillmacky, R. 1992. Effects of leaf rust on selected Australian barleys. Aust. J. Exp. Agric. 32:747-751.

Dracatos, P. M., Singh, D., Bansal, U., and Park, R. F. 2015. Identification of new sources of adult plant resistance to Puccinia hordei in international barley (Hordeum vulgare L.) germplasm. Eur. J. Plant Pathol. 141:463-476.

Ellis, J. G., Lagudah, E. S., Spielmeyer, W., and Dodds, P. N. 2014. The past, present and future of breeding rust resistant wheat. Front. Plant. Sci. 5:641.

Fu, D. L., Uauy, C., Distelfeld, A., Blechl, A., Epstein, L., Chen, X. M., Sela, H. A., Fahima, T., and Dubcovsky, J. 2009. A kinase-START gene confers temperature-dependent resistance to wheat stripe rust. Science 323:1357-1360.

Golan, T., Anikster, Y., Moseman, J. G., and Wahl, I. 1978. A new virulent strain of Puccinia hordei. Euphytica 27:185-189.

Golegaonkar, P. G., Singh, D., and Park, R. F. 2009. Evaluation of seedling and adult plant resistance to Puccinia hordei in barley. Euphytica 166:183-197.

González, A. M., Marcel, T. C., and Niks, R. E. 2012. Evidence for a minor gene-for-minor gene interaction explaining nonhypersensitive polygenic partial disease resistance. Phytopathology 102:1086-1093.

Hickey, L. T., Lawson, W., Platz, G. J., Dieters, M., Arief, V. N., German, S., Fletcher, S., Park, R. F., Singh, D., Pereyra, S., and Franckowiak, J. 2011. Mapping Rph20: A gene conferring adult plant resistance to Puccinia hordei in barley. Theor. Appl. Genet. 123:55-68.

Jin, Y., and Steffenson, B. J. 1994. Inheritance of resistance to Puccinia hordei in cultivated and wild barley. J. Hered. 85:451-454.

Johnson, R. 1981. Durable resistance: Definition of genetic control and attainment in plant breeding. Phytopathology 71:567-568.

Johnston, P. A., Niks, R. E., Meiyalaghan, V., Blanchet, E., and Pickering, R. 2013. Rph22: Mapping of a novel leaf rust resistance gene introgressed from the non-host Hordeum bulbosum L. into cultivated barley (Hordeum vulgare L.). Theor. Appl. Genet. 126:1613-1625.

Krattinger, S., Keller, B., Herrera-Foessel, S., Singh, R., and Lagudah, E. 2013. Letter to the editor. Comment on, In Turkish wheat cultivars the resistance allele of Lr34 is ineffective against leaf rust. J. Plant Dis. Prot. 120:3.

Mace, E. S., Rami, J.-F., Bouchet, S., Klein, P. E., Klein, R. R., Kilian, A., Wenzl, P., Xia, L., Halloran, K., and Jordan, D. R. 2009. A consensus genetic map of sorghum that integrates multiple component maps and highthroughput Diversity Array Technology (DArT) markers. BMC Plant Biol. 9:13.

Marcel, T. C., Varshney, R. K., Barbieri, M., Jafary, H., de Kock, M. J. D., Graner, A., and Niks, R. E. 2007. A high-density consensus map of barley to compare the distribution of QTLs for partial resistance to Puccinia hordei and of defence gene homologues. Theor. Appl. Genet. 114:487-500.

McNeal, F. H., Konzak, C. F., Smith, E. P., Tate, W. S., and Russell, T. S. 1971. A uniform system for recording and processing cereal research data. U.S. Dep. Agric. ARS 34-121. Washington, DC.

Niks, R. E., Walther, U., Jaiser, H., Martinez, F., Rubiales, D., Andersen, O., Flath, K., Gymer, P., Heinrichs, F., Jonsson, R., Kuntze, L., Rasmussen, M., 
and Richter, E. 2000. Resistance against barley leaf rust (Puccinia hordei) in West-European spring barley germplasm. Agronomie 20:769-782.

Park, R. F. 2003. Pathogenic specialization and pathotype distribution of Puccinia hordei in Australia, 1992 to 2001. Plant Dis. 87:1311-1316.

Park, R. F. 2008. Breeding cereals for rust resistance in Australia. Plant Pathol. 57:591-602.

Park, R. F., Golegaonkar, P. G., Derevnina, L., Sandhu, K. S., Karaoglu, H., Elmansour, H. M., Dracatos, P. M., and Singh, D. 2015. Leaf rust of cultivated barley: Pathology and control. Annu. Rev. Phytopathol. 53:565-589.

Park, R. F., and Karakousis, A. 2002. Characterization and mapping of gene Rph19 conferring resistance to Puccinia hordei in the cultivar 'Reka 1' and several Australian barleys. Plant Breed. 121:232-236.

Park, R. F., and McIntosh, R. A. 1994. Adult plant resistances to Puccinia recondita f. sp. tritici in wheat. N. Z. J. Crop Hortic. Sci. 22:151-158.

Parlevliet, J. E. 2002. Durability of resistance against fungal, bacterial and viral pathogens; present situation. Euphytica 124:147-156.

Parlevliet, J. E., and Van Ommeren, A. 1975. Partial resistance of barley to leaf rust, Puccinia hordei. 2. relationship between field trials, micro plot tests and latent period. Euphytica 24:293-303.

Parrott, D. L., Huang, L., and Fischer, A. M. 2016. Downregulation of a barley (Hordeum vulgare) leucine-rich repeat, non-arginine-aspartate receptor-like protein kinase reduces expression of numerous genes involved in plant pathogen defense. Plant Physiol. Biochem. 100:130-140.

Qi, X., Niks, R. E., Stam, P., and Lindhout, P. 1998. Identification of QTLs for partial resistance to leaf rust (Puccinia hordei) in barley. Theor. Appl. Genet. 96:1205-1215.

Qi, X., Niks, R. E., Stam, P., and Lindhout, P. 1999. Erratum: Identification of QTLs for partial resistance to leaf rust (Puccinia hordei) in barley. Theor. Appl. Genet. 98:178.

Riaz, A., Periyannan, S., Aitken, E., and Hickey, L. 2016. A rapid phenotyping method for adult plant resistance to leaf rust in wheat. Plant Methods 12:17.

Roelfs, A. P. 1988. Genetic control of phenotypes in wheat stem rust. Annu. Rev. Phytopathol. 26:351-367.

Sandhu, K. S., Forrest, K. L., Kong, S., Bansal, U. K., Singh, D., Hayden, M. J., and Park, R. F. 2012. Inheritance and molecular mapping of a gene conferring seedling resistance against Puccinia hordei in the barley cultivar Ricardo. Theor. Appl. Genet. 125:1403-1411.

Sandhu, K. S., Singh, D., and Park, R. F. 2014. Characterising seedling and adult plant resistance to Puccinia hordei in Hordeum vulgare. Ann. Appl. Biol. 165:117-129.

Singh, D., Dracatos, P., Derevnina, L., Zhou, M. X., and Park, R. F. 2015. Rph23: A new designated additive adult plant resistance gene to leaf rust in barley on chromosome 7H. Plant Breed. 134:62-69.

Singh, D., Macaigne, N., and Park, R. F. 2013. Rph20: Adult plant resistance gene to barley leaf rust can be detected at early growth stages. Eur. J. Plant Pathol. 137:719-725.

Singh, R. P., Huerta-Espino, J., and Rajaram, S. 2002. Achieving nearimmunity to leaf and stripe rusts in wheat by combining slow rusting resistance genes. Acta Phytopathol. Entomol. Hung. 35:133-139.

Stakman, E., Stewart, D., and Loegering, W. 1962. Identification of Physiologic Races of Puccinia graminis var. tritici. U.S. Dep. Agric. Washington, DC.

Voorrips, R. E. 2002. MapChart: Software for the graphical presentation of linkage maps and QTLs. J. Hered. 93:77-78.

Wenzl, P., Li, H., Carling, J., Zhou, M., Raman, H., Paul, E., Hearnden, P., Maier, C., Xia, L., Caig, V., Ovesna, J., Cakir, M., Poulsen, D., Wang, J., Raman, R., Smith, K. P., Muehlbauer, G. J., Chalmers, K. J., Kleinhofs, A., Huttner, E., and Kilian, A. 2006. A high-density consensus map of barley linking DArT markers to SSR, RFLP and STS loci and agricultural traits. BMC Genomics 7:206.

Wenzl, P., Raman, H., Wang, J. P., Zhou, M. X., Huttner, E., and Kilian, A. 2007. A DArT platform for quantitative bulked segregant analysis. BMC Genomics 8:196.

Yildirim, K., Boylu, B., Atici, E., Kahraman, T., and Akkaya, S. M. 2012. In Turkish wheat cultivars the resistance allele of $L R 34$ is ineffective against leaf rust. J. Plant. Dis. Prot. 119:135-141.

Ziems, L. A., Hickey, L. T., Hunt, C. H., Mace, E. S., Platz, G. J., Franckowiak, J. D., and Jordan, D. R. 2014. Association mapping of resistance to Puccinia hordei in Australian barley breeding germplasm. Theor. Appl. Genet. 127:1199-1212. 